\title{
Estereotipos y humor en el discurso publicitario. A propósito de las dos campañas televisivas de V\&T de Nestea
}

\section{Stereotypes and humor in advertising discourse. The case of two television campaigns of V\&T by Nestea}

Noelia Estévez-Rionegro

Universidade de Santiago de Compostela, Santiago de Compostela noelia.rionegro@usc.es

ACCESO ABIERTO / OPEN ACCESS

Cita: Estévez-Rionegro, Noelia (2021). Estereotipos y humor en el discurso publicitario. A propósito de las dos campañas televisivas de V\&T de Nestea, Textos en Proceso, 7(2), pp. 39-51.

https://doi.org/10.17710/tep.2021.7.

\section{3estevez-rionegro}

Editoras: Esperanza Alcaide Lara (Universidad de Sevilla) y Ana Pano Alamán (Università di Bologna)

Recibido: 21/09/2021

Aceptado: 23/11/2021

Conflicto de intereses: La autora ha declarado que no posee conflicto de intereses.

Copyright: @ Noelia Estévez-Rionegro. Esta obra está bajo licencia Creative Commons Reconocimiento 4.0.

\section{Resumen}

Todo discurso publicitario se crea a partir de mecanismos de argumentación; sin embargo, estos varían, generalmente, en función del efecto perseguido, por lo que pueden llegar a alterarse los patrones básicos para producir una determinada reacción en el destinatario. Es el caso de la contrargumentación y la ironía, que, en clave humorística, impregnan la publicidad audiovisual actual. Los discursos publicitarios contrargumentativos, refutatorios e irónicos resultan especialmente interesantes a nivel sociolingüístico, puesto que las claves necesarias para desambiguar el mensaje están en los topoi o lugares comunes compartidos por las comunidades de hablantes, y a ellos ha de recurrir el destinatario para captar el sentido del discurso. Del conocimiento del mundo, la sociedad y la cultura depende, también, la construcción de los estereotipos, tan presentes en los anuncios publicitarios. La publicidad recrea estereotipos como estrategia de selección de público y de mimetización con el destinatario, de modo que produzca en este una identificación inmediata, que capte su atención y suscite su interés por el producto. De este modo, el discurso publicitario audiovisual se crea acorde a unos patrones de comportamiento social estereotipados que se reflejan no solo a través de la imagen sino también en las manifestaciones lingüísticas, que tratan de emular las propias del estereotipo retratado. Así lo muestra el análisis discursivo realizado a partir de dos campañas publicitarias de un mismo producto, V\&T de Nestea: una de ellas dirigida a un público femenino y la otra, a uno masculino; donde se aprecia cómo se adecuan las estrategias comunicativas al destinatario para construir un discurso que se asocie lingüísticamente al estereotipo y produzca la identificación entre ambos. 
Palabras clave: análisis del discurso, discurso publicitario, publicidad audiovisual, estereotipos femeninos, estereotipos masculinos, lengua oral.

\begin{abstract}
All advertising discourse is created from argumentation mechanisms; however, these vary, generally, depending on the effects sought, so that the basic patterns can be altered to produce a certain reaction in the recipient. This is the case of counterargumentation and irony, which, humorously, pervade current audiovisual advertising. Counter-argumentative, refutative and ironic advertising speeches are especially interesting at a sociolinguistic level, since the keys necessary to disambiguate the message lie in the topoi or common places shared by the speaking communities, and the addressee must resort to them to capture the sense of the speech. The construction of stereotypes, so present in advertisements, also depends on knowledge of the world, society and culture. Advertising recreates stereotypes as a strategy for selecting the audience and mimicking the recipient, so that it produces an immediate identification, which captures their attention and arouses their interest in the product. In this way, the audiovisual advertising discourse is created according to stereotypical social behavior patterns that are reflected not only through the image but also in the linguistic manifestations, which try to emulate those of the stereotype portrayed. This is shown by the discursive analysis carried out from two advertising campaigns for the same product, V\&T by Nestea: one of them aimed at a female audience and the other, at a male audience; where it is appreciated how the communicative strategies are adapted to the addressee to build a discourse that is linguistically associated with the stereotype and produces the identification between both.
\end{abstract}

Keywords: discourse análisis, advertising discourse, audiovisual advertising, female stereotypes, male stereotypes, spoken lenguaje.

\title{
1. Introducción
}

La base fundamental de la publicidad es el mensaje (independientemente del medio o el formato en que se transmita) y su cometido, la persuasión ${ }^{1}$ y la captación de público. Por ello, a lo largo de su historia, los publicistas han ido puliendo y mejorando sus técnicas para lograr conectar del modo más eficaz con el destinatario. Desde los tradicionales anuncios creados en base a fórmulas lingüísticas llanas del tipo compre esto o haga como yo, hasta el empleo de estrategias discursivas trasgresoras que rompen las expectativas del destinatario y producen mayor efectismo.

En la actualidad, los mensajes publicitarios juegan cada vez más con lo implícito, lo sobrentendido, y crean una atmósfera de sugerencias que apela a la mente de un receptor que habrá de inferir el sentido subyacente en el discurso. Se

\footnotetext{
${ }^{1}$ Para comprender mejor la idea de persuasión en publicidad, resulta interesante el estudio de Romero
} Gualda (2010) sobre el componente persuasivo en la construcción sintáctica del discurso publicitario. 
trata de un modo eficaz de atraer la atención del destinatario y vencer su indiferencia. Los publicistas son conscientes de que los anuncios triviales, vanos y simples se olvidan fácilmente, de modo que el impacto en el público es primordial para conseguir el efecto perseguido. Sobre ello reflexiona, por ejemplo, Romero Gualda (2006) en su acercamiento al efecto de lo imprevisible en el mensaje publicitario.

A lo largo de este trabajo, se ilustran algunas de estas técnicas a partir de dos campañas publicitarias de un mismo producto (el refresco $V \& T$ de Nestea) emitidas en televisión en los años 2006 y 2008, pero dirigidas, en cada caso, a un sector del público diferente: mientras el anuncio de 2006 apela a un colectivo femenino, el de 2008 lo hace a su equivalente masculino. Así, a través del análisis discursivo de cada uno de ellos, se pondrán de manifiesto no solo las estrategias lingüísticas que operan en la construcción del mensaje, sino también, y sobre todo, los mecanismos que contribuyen a la recreación del estereotipo y su manifestación en el uso de la lengua.

\section{Estrategias discursivas del mensaje publicitario: la construc- ción del estereotipo}

La argumentación es, como cabe esperar, la base del discurso publicitario; sin embargo, en publicidad, la concepción aristotélica de la argumentación ha ido adquiriendo nuevos matices que la alejan de la idea original. Por ejemplo, Perelman y Olbrechts-Tyteca (1969) consideran que la argumentación tiene como objetivo asegurar la adhesión del público al que se dirige, de modo que concierne, en su totalidad, a las audiencias en las que va a influir. Así, a partir de los conceptos de "audiencias universales" y "audiencias particulares", entienden que el orador puede saber qué información y qué acercamientos alcanzan mayor adhesión tomando como base una audiencia ideal. Frente a la restricción al ámbito civil que Aristóteles aplicaba a la retórica epidíctica, para Perelman (1969) tiene gran importancia en la argumentación, porque determina la disposición de la audiencia a la acción y aumenta la adhesión a los valores que exalta.

Anscombre y Ducrot (1988) también reformulan la teoría de Aristóteles y proponen un nuevo enfoque de sus postulados: un argumento, afirman, no es un conjunto de estrategias verbales cuya función es la persuasión, sino un encadenamiento de enunciados conducentes a una conclusión. El componente retórico ya no es algo orientado a una disciplina extralingüística, sino que forma parte del sentido del enunciado. Retórica y lingüística se conjugan, de este modo, como aspectos esenciales del discurso inductivo y proselitista. En la misma línea se enmarca Amossy (2000), para quien el anuncio publicitario debe valerse de la retórica para construir un mensaje con función argumentativa y finalidad persuasora.

Paralelamente a esta renovada idea de argumentación, surge la de contrargumentación (López Díaz, 2010), que consiste en un giro sarcástico por el que el mensaje publicitario resulta negado, de modo que se invita al receptor a reconocer irónica e implícitamente las cualidades del producto determinado. El conocimiento lingüístico de los hablantes, así como de los topoi o lugares comunes consensuados, permiten que el mensaje sea captado en su plenitud: a partir de los 
argumentos refutatorios el destinatario apelará a su memoria para prolongar su razonamiento hasta encontrar un eco positivo.

Sin embargo, aunque los argumentos sean negativos y no contribuyan, en principio, a la positivización del producto, el efecto resulta igualmente eficaz, pues el destinatario posee los conocimientos necesarios para desambiguar el mensaje. Así, no solo se consigue la finalidad perseguida, sino que además se estimula la atención del receptor, desafiando su entendimiento y creando con él una cierta complicidad. A este respecto, resultan muy interesantes las siguientes palabras de Adam y Bonhome:

\begin{abstract}
A pesar de su carácter a veces incisivo, estas refutaciones siguen, claro está, bajo el control del anunciante. Al aceptar desvelarlas, busca desbaratar de antemano las acusaciones de manipulación de un público pasivo y crédulo. Esta manera de ponerse en entredicho a sí mismo permite al discurso publicitario romper con la presentación aséptica de la mayoría de los anuncios y dialectizar su mensaje. El control sigue siendo total, ya que, como las refutaciones no quedan nunca sin respuesta, el anunciante neutraliza sistemáticamente todo riesgo de que se destroce su argumentación (1997, p. 55).
\end{abstract}

Además, como la argumentación, también la contrargumentación participa del esquema funcionalista de los constituyentes de la comunicación de Jakobson (1963): emisor (representante tras el que se oculta la figura del comerciante), receptor (destinatario al que se persuade para convertirlo en "cliente") y mensaje (argumentos orientados a la glorificación del producto y de su universo). La publicidad no solo explota estos elementos hasta el límite, sino que va más allá, pues introduce nuevos componentes comunicativos como el "contacto", cuya meta es llamar la atención del receptor, o el "código", que concierne precisamente a aquellos casos en los que el discurso parece estar desestructurado, como señalan Adam y Bonhome (1997, pp. 40-41).

El componente irónico y humorístico es inseparable de los discursos publicitarios contrargumentativos (Estévez-Rionegro, 2021), y constituye la clave a partir de la cual el destinatario puede inferir y desambiguar el mensaje. El humor en la publicidad ha sido definido como un procedimiento enunciativo en el que confluyen fenómenos lingüísticos y no lingüísticos para producir un desequilibrio a través de un signo o icono incongruente, que sale de las normas establecidas y muestra una visión del mundo poco habitual, volviendo extraño lo familiar y otorgándole al mensaje un tono liviano, como indica López Díaz (2008). De este modo, el anuncio choca con las expectativas de un público acostumbrado a los discursos publicitarios prototípicos, serios y de sentido común.

La enunciación humorística, en oposición a la seria, dota al discurso de un tono discordante, aportando otra visión de las cosas que desdobla e instaura una mentalidad anticonformista. Como fruto de esa transgresión emergen anomalías en el discurso. A este respecto, resulta interesante el estudio de Gómez Torrego y Robles Ávila (2014) sobre las transgresiones idiomáticas en la publicidad, donde analizan los usos y abusos lingüísticos habituales de los anuncios publicitarios.

Las expresiones de humor más relacionadas con la contrargumentación son las ironías o antífrasis y las paradojas, ya que entrañan una contradicción en el propio discurso que lleva a su refutación. Desde el punto de vista de la lógica, estos enunciados son siempre falsos, aporías que no conducen a un resultado racional, 
pero desde el punto de vista lingüístico, son significativos, en tanto que concilian elementos incompatibles o contradictorios.

Otros estudios recientes sobre el discurso publicitario exploran el humor en relación con la persuasión y la argumentación. Así, Urbina Fonturbel (2020) entiende la publicidad como un ejemplo de construcción textual argumentativa, cuya finalidad es la persuasión. Su estudio aúna dos perspectivas: la de la teoría de la argumentación (que se basa en la relación, la intención y la fuerza argumentativas) y la del análisis del discurso (donde la publicidad gira en torno al ethos, al logos y al pathos). La función del emisor es, de acuerdo con el autor, establecer la imagen de marca dentro del anuncio y llegar eficazmente al destinatario. Para este propósito, el humor es una de las mejores estrategias, puesto que se basa en tópicos y en elementos emocionales para lograr el vínculo entre la marca y el público. De este modo, Urbina Fonturbel termina de perfilar la línea de investigación iniciada en 2018 con el estudio de la publicidad en clave humorística desde el punto de vista de la retórica y el análisis del discurso ${ }^{2}$.

Dejando al margen las consideraciones lingüísticas, es importante destacar que, detrás de todo spot publicitario, siempre hay un tipo de personalidad retratada: los códigos no se usan solo para convencer a las masas, sino también para dotar al objeto de una identidad que se recrea en un determinado arquetipo social.

De este modo, resulta pertinente hablar de una publicidad del estereotipo, pues emula las características de un grupo social concreto (con unas cualidades, aficiones, inquietudes o atributos específicos). El mensaje emerge impregnado de convenciones asociadas al sector al que es dirigido, lo que se manifiesta tanto en la forma como en el contenido del discurso. La clave radica en la importancia de las alusiones culturales o sociales que refuerzan los topoi o conocimientos compartidos: el entenderlas hace sentir al individuo miembro de la colectividad. Por ello, es muy recurrente entre los publicistas el retomar experiencias de la vida cotidiana, hábitos y costumbres compartidos por la comunidad, saberes universales, etc.

La publicidad no crea en absoluto estereotipos, sino que los retoma de la realidad existente para utilizarlos como instrumentos de cohesión social. Tanto los estereotipos como los topoi son principios generales consensuados en una comunidad lingüística o social, de modo que el interlocutor que los evoca no se presenta como su autor sino como usuario.

En estrecha relación con la teoría del estereotipo se encuentra, también, la noción del prototipo. Si algo se estereotipa no es sino porque se ha forjado un prototipo al que imitar. Rosch (1977) define el concepto de prototipo como un "esquema cognitivo que se confunde con el mejor ejemplar de la categoría". En este sentido, la categorización descansa en la tipicidad y la gradualidad, donde los confines entre miembros centrales y periféricos se desdibujan. Sin embargo, en el discurso publicitario las categorías están establecidas de antemano: el protagonista se presenta como un sujeto prototípico e ideal en busca de sus atributos, aquellos que la publicidad puede satisfacer si encuentra una fórmula óptima con la que ofrecerlos.

${ }^{2}$ Vid. Urbina Fonturbel (2018). 


\section{Análisis discursivos de las campañas publicitarias de McCann Erickson para V\&T de Nestea}

En 2006 se produjo el lanzamiento de $V \& T$ de Nestea, una nueva bebida de la marca Coca-Cola que, pese a lo invertido en efectismo publicitario, apenas duró unos años en el mercado, convirtiéndose en una moda pasajera. Del refresco se rodaron dos anuncios publicitarios para televisión que se emitieron en España en los años 2006 y 2008. Ambos fueron creados por la empresa de publicidad McCann Erickson y el segundo no es sino resultado del éxito alcanzado por el primero. En la actualidad, los anuncios están alojados en internet y pueden encontrarse en Youtube y Dailymotion. Se han conservado, principalmente, en recopilatorios de anuncios televisivos que pretenden mostrar el efectismo que la publicidad audiovisual alcanza en el siglo XXI, aunque no deja de ser llamativo que, pese a la inversión de la marca en publicidad, el producto no lograse calar en el mercado, especialmente, tras la segunda campaña publicitaria, la versión masculina.

Las dos campañas emulan la serie televisiva Sexo en Nueva York, con un decorado que recuerda las calles de Manhattan donde transcurre la mayor parte de los capítulos de la serie y unos iconos estereotipados que remiten a los principales personajes de la misma. De este modo, se hace un guiño a los seguidores del programa, especialmente al sector femenino que comparte el estilo de vida de las protagonistas de la serie y que es, por tanto, el estereotipo representado en el primer anuncio y el que, de algún modo, también condiciona el segundo.

\section{1. Primera campaña publicitaria: la versión femenina}

La campaña publicitaria de 2006 muestra, en tono humorístico, distintas situaciones cotidianas de mujeres que simulan no preocuparse por su físico, al considerar que su belleza es una cualidad intrínseca que no necesita cuidados. Sin embargo, a lo largo del spot se van revelando, progresivamente, diversos trucos que contribuyen secretamente al mantenimiento de ese atractivo, de entre los cuales, el más importante, es el consumo del refresco $V \& T$ de Nestea. Así se lanzaba al mercado, aquel año, una nueva bebida que satisfacía las necesidades de un público femenino adulto, urbano y cosmopolita, preocupado por las nuevas tendencias, la salud y la calidad de vida. Todo ello en conjunción con un discurso que, como se muestra a continuación, supone un prolongado sarcasmo que, poco a poco, se va desambiguando a sí mismo. Reza así:

1) A ver, las mujeres tenemos una curiosa percepción de la realidad: nunca diremos "te sobran unos kilos", diríamos "uy, si es que estabas demasiado flaca”. Mentimos sobre el aspecto de otras personas; pero, sobre el nuestro, oh ¡mentimos mil veces más! (Voy al gimnasio solo para romper con la rutina ¿eh?)

La mentira es directamente proporcional a la belleza: cuanto más guapas, menos reconocemos lo que nos cuesta serlo. Una mujer guapa nunca, nunca se cuida. Por eso, el nuevo V\&T de Nestea, con antioxidantes procedentes del té verde, es un refresco que yo no necesito porque yo no me cuido.

V\&T de Nestea, nuestro secreto.

Es evidente que el anunciante se dirige a un sector del público muy concreto, que comulga con el estilo de vida mencionado y que, por tanto, sabrá 
inmediatamente que el producto que se publicita está pensado para él. Los argumentos empleados en el discurso se dirigen de forma directa a la mente de estos posibles compradores, y lo hacen, además, a través de una serie de técnicas que resultan muy efectivas a la hora de atraer su atención y vencer su posible indiferencia. Se trata de algunas de las estrategias transgresoras mencionadas con anterioridad, como la contrargumentación, el humor y la ironía.

El spot constituye un claro ejemplo de ironía refutatoria en clave humorística. El discurso se presenta como un largo sarcasmo donde los argumentos resultan un tanto ambiguos. Comienza con una rotunda y estereotipada afirmación sobre el sexo femenino (las mujeres tenemos una curiosa percepción de la realidad) que se aparta de las expectativas del oyente (quien, a priori, esperaría un consejo publicitario clásico) para, a continuación, justificarla con una serie de ejemplos que contribuyen a sustentar esa idea (nunca diremos "te sobran unos kilos", diríamos "uy, si es que estabas demasiado flaca"). A través de esta paradoja se ofrece al receptor la primera clave para captar la intención del mensaje: sabe que lo que se afirme será desde la perspectiva de un prototipo de mujer que concibe la realidad de una manera un tanto especial. Inmediatamente después, se introduce un nuevo argumento irónico que pone en entredicho la franqueza del colectivo femenino, pues no resalta, como cabría esperar, sus atributos, sino que expone cualidades negativas: Mentimos sobre el aspecto de otras personas; pero, sobre el nuestro, oh ;mentimos mil veces más! Se juega con el concepto de "mentira" como elemento clave para que el oyente se percate de la dirección que sigue el discurso. Nuevamente, se acude al recurso de la ironía al introducir el siguiente enunciado a modo de ejemplo práctico que recrea situaciones de la vida cotidiana de ese estereotipo femenino: Voy al gimnasio solo para romper con la rutina, ¿eh?

A partir de aquí, el destinatario, probablemente, habrá captado el componente irónico del mensaje publicitario, y esto posibilita la inclusión de un tercer argumento, en el mismo tono, que asocia los términos de "mentira" y "belleza" como conceptos inseparables: La mentira es directamente proporcional a la belleza: cuanto más guapas, menos reconocemos lo que nos cuesta serlo. Y, con esa inocente "confesión", el mensaje llega al culmen de la ironía, al introducir una afirmación contundente y rotundamente sarcástica mediante la figura retórica de la antífrasis: Una mujer guapa nunca, nunca se cuida.

El mensaje, aunque socarrón y contradictorio, es eficaz como reclamo, pues está perfectamente estructurado en cuanto a los momentos de mayor ironía, los ejemplos empleados y las claves y guiños que permiten deshacer la ambigüedad de los enunciados. Todo ello permite introducir, de forma desenfada, una refutación del producto que se ofrece, pues el destinatario ya conoce la clave sarcástica en que se desarrolla el discurso. De este modo, mediante un marcador discursivo consecutivo (por eso), se introduce en el discurso la consecuencia de lo dicho previamente, y esta nueva afirmación resulta especialmente chocante porque parece realizar una objeción sobre el producto anunciado. Si bien es cierto que se resaltan sus características con la finalidad de positivizarlo, acaba rechazándose por ser innecesario para el tipo de mujer descrito: Por eso, el nuevo $V \& T$ de Nestea con antioxidantes procedentes del té verde es un refresco que yo no necesito, porque yo no me cuido. De nuevo, el publicista recurre a la antífrasis como técnica retórica. 
Finalmente, el resultado motivado por el sentido del mensaje es un simple razonamiento silogístico: si las mujeres tienen el hábito de mentir, cuando dicen que no necesitan $V \& T$ para cuidarse están haciendo uso de la falsedad que las caracteriza.

Aunque es esperable que el destinatario haya desentrañado perfectamente el sentido del discurso, el anuncio revela explícitamente su intención oculta en el colofón: el tipo de mujer que recrea el spot cuida concienzudamente su aspecto y su salud, por lo que $V \& T$ es su bebida ideal, pese a haberlo negado de acuerdo con los códigos propios del estereotipo ( $V \& T$ de Nestea, nuestro secreto).

Pero, además, en el anuncio audiovisual es imprescindible la interconexión del discurso con la imagen ${ }^{3}$. Cada una de las situaciones que se van relatando se apoyan en elementos visuales que representan las acciones desde el punto de vista de la protagonista del spot: una mujer joven, desenfadada y atractiva, que emite su discurso portando en su mano, en todo momento, el refresco en cuestión, y mostrándose, en efecto, fiel consumidora.

La voz enunciativa remite, por tanto, a un determinado estereotipo femenino, cuyo modo de expresarse subyace en un discurso que se configura en base a los rasgos lingüísticos conversacionales que comúnmente se le asocian ${ }^{4}$.

Uno de los aspectos que caracteriza el habla de las mujeres es el deseo de incluir "como iguales" en el discurso a los participantes, por lo que utilizan estrategias como la muestra de interés hacia el interlocutor o la alabanza ajena. El anuncio que nos ocupa acata esta técnica desde el primer instante, mediante constantes fórmulas que identifican al destinatario con el emisor del mensaje: desde unidades léxicas como mujeres o mujer guapa hasta elementos gramaticales como las desinencias verbales en primera persona del plural (tenemos, diremos, mentimos, reconocemos...), los pronombres personales (nos) o los determinantes posesivos (nuestro), es decir, plurales que acercan a la entidad emisora al colectivo de destinatarios. Pero, además, el mensaje parece caer en una especie de "metadiscurso" que parodia ese mismo modo de expresarse en lo que a la alabanza ajena se refiere, y lo hace emulando de forma irónica una escena típica de la vida cotidiana entre dos conocidas: nunca diremos "te sobran unos kilos", diríamos "uy, si es que estabas demasiado flaca". Este tipo de recursos, como halagos y cumplidos, suelen ser utilizados con una función de solidaridad y reconocimiento, que busca la equidad entre los participantes del acto comunicativo.

Así, la mayor parte de los enunciados del spot se construyen en plural, a excepción de la secuencia una mujer guapa nunca, nunca se cuida que, a modo de sentencia o saber universal, también señala al colectivo, al estereotipo que emula el anuncio y cuya función es la misma que la perseguida por los elementos décticos en plural: lograr que el destinatario se identifique con la entidad emisora.

Contrariamente, hacia el final del discurso, el plural enunciativo se transforma en un singular que sitúa al emisor como representante modélico del grupo, como un prototipo al que los demás habrán de imitar: es un refresco que yo

\footnotetext{
${ }^{3}$ Véase, por ejemplo, Salway y Martinec (2002).

${ }^{4}$ Pueden consultarse a este respecto los trabajos de Lozano Domingo (1995), García Mouton (2003) o Calero Fenández (2013) sobre tópicos y creencias en torno a los usos femeninos y masculinos del lenguaje.
} 
no necesito, porque yo no me cuido. De esta manera, la protagonista se sitúa como el icono que sirve de reclamo para satisfacer las necesidades de los miembros del colectivo, puesto que, bajo el pronombre singular de primera persona, subyace, en realidad, una conciencia grupal.

Otro de los mecanismos empleados por los publicistas para construir el discurso es la recurrencia a clichés, formulismos y muletillas comúnmente asociadas al habla femenina. Las mujeres suelen prestar atención a las palabras ajenas y a los mensajes externos, tanto verbales como no verbales. Por esa razón, aunque no dudan en lo que desean decir, suelen dar rodeos al expresar sus ideas, porque se preocupan por el efecto que sus palabras puedan provocar en los interlocutores. Generalmente, y en base al estereotipo, las mujeres tratan de no resultar pedantes ni severas en sus conversaciones, de modo que, a menudo, apelan a expresiones que modulan sus aserciones y mitigan la fuerza de la expresión, con el objetivo de esquivar una posición de superioridad. Así, de acuerdo con Tannen (1990) en el estilo femenino, se emplean mucho las expresiones estándar, lo que supone una huida de las expresiones vulgares y groseras, para evitar herir a los interlocutores. Por ejemplo, las mujeres se involucran en la conversación cooperando con preguntas (¿tú crees?), comentarios ( ya, sí, claro), exclamaciones ( $u y, o h, ~ ¿ e h$ ?), interjecciones (ajá), onomatopeyas ( $\mathrm{mmm}$ ) o risas, que actúan como muletillas. Además, acuden notablemente a elementos modalizadores (entendidos como un conjunto de piezas que manifiestan la posición de quien habla respecto a lo que dice), como expresiones hiperbólicas (nunca, nunca), que enfatizan la locución.

Como se puede apreciar, los elementos de la lengua constituyen la base de la estrategia publicitaria, al apelar a realidades sociolingüísticas y experimentar al máximo con los códigos verbales. Las múltiples posibilidades que ofrece el idioma se explotan para lograr efectismo en el discurso, pero sin quebrantar los pilares de la retórica ni renunciar a los principios de la argumentación. Los publicistas se valen del humor para parodiar no solo un estereotipo sino también el discurso que se le asocia, incluso desde la perspectiva de género.

\section{2. Segunda campaña publicitaria: la versión masculina}

El éxito alcanzado en la campaña publicitaria de 2006 llevó a McCann Erickson a repetirla de un modo similar en 2008 pero, esta vez, con un emisor masculino como protagonista. Con una ambientación similar, el nuevo spot retrata los tópicos de la simplicidad y las habilidades para seducir a las mujeres que comúnmente se asocian al estereotipo masculino.

Aunque cada campaña publicitaria presenta unas estrategias discursivas diferentes, no se puede perder de vista el hecho de que un anuncio derive de otro, porque esto establece las claves interpretativas del más reciente. Así, resulta interesante contrastar la construcción del discurso en cada caso y la recreación del estereotipo desde la perspectiva de género que surge con la introducción de un protagonista masculino, pero teniendo presente el tono humorístico y paródico iniciado con la primera campaña publicitaria y el punto de vista del colectivo femenino al que era destinado. En otras palabras: si la versión masculina deriva de la femenina, cabe pensar que el punto de vista desde el que se retrata la figura del 
hombre sigue siendo el femenino, de modo que se recrea el estereotipo masculino bajo la óptica de aquellas mujeres a las que se dirigía la primera campaña.

El mensaje publicitario de 2008 reza así:

2) Se supone que los hombres somos muy simples. Si hay un refresco que nos gusta, pues lo bebemos, como $V \& T$.

$[(())]$

Con antioxidantes naturales del té verde que ayudan a cuidarte y, además, con el tema de conversación con las mujeres; porque una cosa es ser simple y, otra, no tener una estrategia.

$V \& T$ de Nestea, la excusa para ayudar a cuidarte.

Como se puede observar, el spot repite las mismas estrategias de adhesión al receptor de la versión femenina: el emisor se presenta como portavoz del colectivo al que se dirige, como un estereotipo modélico que aconseja al grupo. Al igual que en la versión femenina, por medio de los deícticos en primera persona de plural, el protagonista se erige como representante del grupo, lo que produce la identificación del emisor con el destinatario desde el primer instante (los hombres somos muy simples; si hay un refresco que nos gusta, pues lo bebemos). La ruptura se produce en la segunda parte, cuando la voz enunciativa apela, en segunda persona, al destinatario para lanzarle un consejo que se revela como una estrategia clave en el cuidado físico y afectivo (ayudan a cuidarte y, además, con el tema de conversación con las mujeres). El enunciado finaliza con una aserción en forma no personal que trata de sustentar los argumentos recién expuestos, mediante el uso de infinitivos que impersonalizan el mensaje y le dan la apariencia de saber universal: porque una cosa es ser simple y, otra, no tener una estrategia. Con ello, se introduce un eco positivo que resalta una cualidad masculina y que compensa, en cierto modo, el tópico inicial. Sin embargo, la cualidad destacada, nuevamente, remite a un estereotipo: el tópico donjuanesco o la capacidad masculina para seducir mediante argucias. Es en este punto donde cabe recordar la relación con la primera campaña publicitaria y el imperio de la visión de un determinado estereotipo femenino que se hace extensivo a la segunda campaña. De este modo, no podemos afirmar que se esté parodiando un estereotipo masculino generalizado, sino más bien la imagen que tiene sobre los hombres el colectivo de mujeres del anuncio anterior, es decir, el pensamiento propio del estereotipo femenino con el que conversa el segundo spot.

En la secuencia final, eslogan de la campaña publicitaria, la voz enunciativa retoma la segunda persona gramatical para emitir su último consejo y la conclusión de la argumentación: $V \& T$ de Nestea, la excusa para ayudar a cuidarte. El enunciado se construye, estratégicamente, posponiendo el verbo, de modo que el pronombre clítico de segunda persona, que señala al oyente, cierra la construcción.

A grandes rasgos y de acuerdo con Tannen (1990), el discurso masculino se presenta como fuertemente jerarquizado. Los hombres no buscan incluir como iguales a los participantes del acto comunicativo, sino que sienten la necesidad de autoafirmarse, de conseguir el liderazgo. Esta posición de dominación se logra, a través del habla, al pretender estar perfectamente informado de los temas de interés para tratar de sonar experto en la materia. Además, suelen ser directos y asertivos, 
y emplear una entonación enérgica, despojada de sentimentalismos y valoraciones afectivas. También suelen presentar menos alternancias que las mujeres en el tono y menos dinamismo, por lo que consiguen parecer más diestros en el tema y no mostrarse implicados en él emocionalmente. Por último, en su discurso no son habituales los modalizadores, las exclamaciones ni otras expresiones a modo de muletillas, como puede apreciarse a lo largo del spot.

La voz enunciativa, en tono paródico, hace uso de esa "simpleza" que caracteriza al estereotipo al que remite y elabora un discurso sencillo, conciso, explícito y directo. Los elementos deícticos se conjugan en perfecta armonía entre la primera persona y la segunda, el plural y el singular. Por su parte, los enunciados se construyen mediante argumentos cómicos pero positivos, que no refutan ni cuestionan el producto, como ocurría en la versión femenina del anuncio. Las técnicas empleadas por los publicistas son prácticamente idénticas: en ambos se simulan los hábitos de un sector social concreto y se imitan los rasgos conversacionales propios del mismo. Sin embargo, el modo de elaborar el discurso publicitario es muy diferente en uno y otro caso. La alteración de los códigos, los efectos transgresores y las anomalías logran un impacto superior en el receptor, suscitan más interés y logran que el producto alcance un mayor reconocimiento.

\section{Conclusiones}

A lo largo de estas páginas, se muestra cómo el lenguaje publicitario contribuye a construir y perpetuar los estereotipos sociales, con especial atención al género. A partir del análisis de las dos campañas publicitarias del refresco $V \& T$ de Nestea emitidas en España en 2006 y 2008, se han trazado, desde la praxis, algunos de los mecanismos lingüísticos que operan en la construcción del discurso publicitario, centrados, especialmente, en los recursos retóricos de la argumentación y la contrargumentación, el humor y la ironía como estrategias de persuasión que suponen una transgresión de las tradicionales. Pero, sobre todo, se ha demostrado cómo los discursos para publicitar un mismo producto se construyen de un modo diferente en función del destinatario. Así lo muestra cada uno de los anuncios examinados, donde tanto el aspecto del emisor como su discurso y su forma de expresarse emulan los propios del estereotipo social al que se dirige el mensaje, con la finalidad de que esa mímesis consiga que el destinatario se identifique con él y muestre interés por el producto. En los casos analizados, se recrea el mismo estereotipo social (mediana edad, urbano, atractivo, desenfadado) desde dos géneros diferentes: el femenino y el masculino, y las principales diferencias entre ellos se manifiestan, como hemos visto, en el uso del lenguaje. De este modo, las claves para interpretar el sentido del mensaje dependen de los topoi o lugares comunes de los hablantes, que captarán el sentido del mensaje apelando a su conocimiento del estereotipo social recreado.

El lenguaje empleado en la construcción del discurso de cada campaña publicitaria resulta tan estereotipado como la imagen social que muestra, ya que cae en clichés como la jerarquización del habla masculina, la búsqueda de liderazgo en la conversación o la autoafirmación, frente a la solidaridad, la alabanza ajena o el empleo de muletillas que se suelen atribuir al habla femenina. Así, en el discurso de los anuncios analizados, el humor y la parodia terminan contribuyendo a perpetuar los estándares sociales y de género tradicionalmente estereotipados. 


\section{Referencias}

1. Adam, J. M. y Bonhome, M. (1997). La argumentación publicitaria. Madrid: Cátedra, 2000

2. Amossy, R. (2000). L'argumentation dans le discours. Paris: Nathan Université.

3. Anscombre, J. C. y Ducrot, O. (1988). La argumentación en la lengua. Madrid: Gredos, 1994.

4. Calero Fernández, M. Á. (2013). Análisis sociolingüístico de las creencias en torno al habla femenina y al habla masculina. En Montoya Abat, B. y Mas i Miralles, A. (Coords.); Gimeno-Menéndez, F. (Hom.), Studia linguistica in honorem Francisco Gimeno Menéndez (pp. 353-374). San Vicent del Raspeig: Publicacions de la Universitat d'Alacant.

5. Estévez-Rionegro, N. (2021). Estrategias discursivas de la denominada antipublicidad. En Cid Fernández, X. M., García Señorán, Ma del M., Mociño González, I. (Coords.), Novas realidades, novas reflexións e propostas de acción (pp. 207-219). Santiago de Compostela: Andavira.

6. García Mouton, P. (2003). Así hablan las mujeres: curiosidades y tópicos del uso femenino del lenguaje. Madrid: La esfera de los libros.

7. Gómez Torrego, L. y Robles Ávila, S. (2014). Transgresiones idiomáticas en el lenguaje de la publicidad. Madrid: Cátedra

8. Jakobson, R. (1963). Ensayos de lingüística general. Barcelona: Planeta, 1985.

9. López Díaz, M. (2008). El humor como procedimiento discursivo en los anuncios publicitarios. Revie Romane, 43 (1), pp. 25-62. https://doi.org/10.1075/rro.43.1.03lop

10. López Díaz, M. (2010). Quand un discours feint d'argumenter contre lui-même. En Iliescu, M., Sillei-Runggaldier H. y Danler, P. (Eds.), Actes du XXV Congrès International de Linguistique et Philologie Romanes (Innsbruck, 3-8 septembre 2007) (pp. 467-476). Berlin: Walter de Gruyter. https://doi.org/10.1515/9783110231922.5-467

11. Lozano Domingo, I. (1995). Lenguaje femenino, lenguaje masculino. ¿Condiciona nuestro sexo la forma de hablar? Madrid: Minerva Ediciones.

12. Perelman, C. y Olbrechts-Tyteca, L. (1969). The new rhetoric: A treatise on argumentation. Notre Dame: University of Notre Dame Press.

13. Perelman, C. (1969). Le Champ de l'argumentation. Bruxelles: Presses Universitaires de Bruxelles.

14. Plantin, C. (1998). La argumentación. Barcelona: Ariel.

15. Roch, E. (1977). Human Categorization. En Warren, N. (Ed.), Advances in CrossCultural Psychology (pp. 1-72). London: London Academic Press.

16. Romero Gualda, M. V. (2006). Lo imprevisible en el mensaje publicitario. En Casado Velarde, M., González Ruiz, R. y Romero Gualda, M. V. (Coords.), Análisis del discurso: lengua, cultura, valores: Actas del I Congreso Internacional (Vol. 1, pp. 775-788) Madrid: Arco Libros.

17. Romero Gualda, M. V. (2010). Persuasión y sintaxis publicitaria. En Robles Ávila, S. y Romero Gualda, M. V. (Coords.), Publicidad y lengua española: un estudio por sectores (pp. 150-162). Zamora: Comunicación Social Ediciones y Publicaciones.

18. Salway, A. y Martinec, R. (2002). Some ideas for modeling image-text combinations. http://epubs.surrey.ac.uk/508/1/fulltext.pdf. Fecha de consulta: 20/11/2021

19. Tannen, D. (1990). You Just Don't Understand: Women and Men in Conversation. New York: Ballantine.

20. Urbina Fonturbel, R. (2020). La función del 'delectare' en la argumentación publicitaria: el humor como estrategia persuasiva en la publicidad. Language Design: Journal of Theoretical and Experimental Linguistics, Vol. extra 1, pp. 17-30.

21. Urbina Fonturbel, R. (2018). El humor en la publicidad desde la perspectiva de la retórica y el análisis del discurso. Actio Nova: Revista de Teoría de la Literatura y Literatura Comparada, Vol. extra 2, pp. 44-72. 
ASI $(\mathrm{E} \quad$ tep

\section{Corpus documental}

22. Versión femenina: https://www.youtube.com/watch?v=lYP1_1Hf414 (minuto 0:15 a 0:45) Fecha de consulta: 20/11/2021.

23. Versión masculina: https://www.dailymotion.com/video/x4pfp3 Fecha de consulta: 20/11/2021. 